\title{
Tackling the Confusing Words of Strategy: Effective Use of Key Words for Publication Impact
}

\author{
Eric W. Ford \\ Social Learning Solutions \& Department of Management, Bryan School of Business and \\ Economics, University of North Carolina Greensboro \\ PO Box 26170, Greensboro, NC, U.S.A. \\ Tel: 1-336-334-4524 E-mail: ewford@uncg.edu
}

Zhonghui Wang

Department of Management, Bryan School of Business and Economics, University of North Carolina Greensboro

PO Box 26170, Greensboro, NC, U.S.A.

Tel: 1-336-256-8591Ｅ-mail: zhonghui-wang@uncg.edu

Received: November 17, 2013 Accepted: February 19, 2014 Published: April 14, 2014

doi:10.5296/bms.v5i1.4573 URL: http://dx.doi.org/10.5296/bms.v5i1.4573

\begin{abstract}
The tremendous growth of the strategic management field has not mitigated the problem of lack of consistency in terminology. To make things even worse, general-purpose catalogs, such as ABI and Social Sciences Citation Index (SSCI) have developed inconsistent lists of strategy terms. The phenomenon weakens the legitimacy of the field as a normal science. Based on extensive review of business indices and high quality business journals, we help address this problem by proposing a taxonomy for strategic management scholars to use in key word selection. This effort is rendered in a three-step approach. First, we identify terms associated with strategy by investigating two different types of databases, which are general indices such as ABI/INFORM and the Permuterm Subject Index (PSI) and journal indexes. Second, we record an explicit definition for each of the terms identified. Finally, we eliminate any terms that were clearly not relevant to the field of strategy based on criteria established
\end{abstract}




\section{Macrothink}

Business Management and Strategy ISSN 2157-6068 2014, Vol. 5, No. 1

ex post selection of the terms. To complement our key word selections, we further propose a preliminary draft of an indexing system based on the Journal of Economics (JEL) model. Taken together, our research proposes a mechanism which can be used by the strategic management field to help researchers signal the subject and scope of their studies more effectively.

Keywords: Strategy, Taxonomy, Proposed Index 


\section{Introduction}

Milton Leontiades' (1982) article, 'The Confusing Words of Business Policy,' discussed the lack of consistency in strategy and business policy terminology and called for increased uniformity. He considered clarification important for two reasons. First, it would create a common language and thus enable researchers to communicate the results of their scholarly endeavors with greater clarity (Nicolai \& Dautwiz, 2010). Second, it would aid in defining areas or streams of strategy research (Ronda-Pupo \& Guerras-Martin, 2012). If terms were confusing in 1982, the proliferation of new variants can only be characterized as chaotic in the time since, as the strategic management field has experienced a series of paradigm shift (Hoskisson, Hitt, Wan, \& Yiu, 1999)

Fostering confusion is the absence of any agreed upon taxonomy for research topics. Defining and calling for needed research is difficult without a common framework. Other disciplines, such as economics and medicine for example, have well developed classifications schemes to track and access literature. Management science in general, and strategy in particular, would benefit greatly if a taxonomy was available. Otherwise, it would be difficult for the strategic management field to truly achieve the legitimate status of normal science (Kuhn, 2012).

In the absence of a common taxonomy, general-purpose catalogs, such as ABI and Social Sciences Citation Index (SSCI) have developed inconsistent lists of strategy terms. Adding even more confusion, various strategy-oriented journals produce their own, unique annual indexes. Historically, most journals' indexing was inconsistent from year-to-year and varied with changes in editorial staffs. More recently, the explicit indexing of journals' contents by editors has by-in-large come to an end with the ubiquity of electronic search tools (Schendel, 2006). While electronic searches increase the size of the net cast (i.e., 'sensitivity' in statistical terms), the exactness (i.e., 'specificity') is much lower in identifying articles that are likely to be relevant. As a result, searching for relevant strategy research materials becomes more difficult in some instances.

The purpose of this paper is to propose a taxonomy for strategic management studies. To achieve these goals this paper has three main parts. First, a discussion of the need for unified research taxonomy is presented. Second, the major terms relating to the strategy field are distilled from business indices and high quality business journals. Particular attention is given to terms that include some form of the word strategy. In addition, a review of the historic systems used by management journal editors for classifying strategy literature is also provided in this section. Third, a preliminary draft of a proposed indexing system is presented based on the Journal of Economics (JEL) model.

The single biggest advantage to modeling the strategy classification scheme after the economic tradition is convenience. Also, a great deal of strategy theory is grounded in economics, further facilitating the adaptation process. Finally, the JEL system is structured so that a single code conveys several layers of information. A taxonomy designed in this fashion 
allows for different streams of literature to evolve with only slight additions to the existing system.

\section{Background}

As the discipline of strategy grew in popularity many areas of business management research took an interest. One popular method for fields such as marketing and human resources to take part in the phenomena was to simply add a strategic component to their own areas (Barry $\&$ Elmes, 1997). Much of this growth occurred prior to the renaming of the domain from 'Business Policy' to 'Strategy', which began to take place with the publication of Strategic management: A new view of business policy and planning (Schendel \& Hofer, 1979).

It is interesting to note that the acceptance of 'strategy' as the designation for the field occurred without any common definition of strategy itself. Later, Leontiades (1982) argued to restrict the scope of the term; "Strategy is a very important element of planning and in some cases may be the dominant element. But strategy is part of the process and not the whole of it" (p. 46). Nevertheless, most authors took a broader approach and accept Chandler's (1962) interpretation that, "Strategy can be defined as the determination of the basic long-term goals and objectives of an enterprise, and the adoption of courses of action and the allocation of resources necessary for carrying out these goals" (p. 13).

In fact, Mintzberg (1978) used the Chandler' quote to describe intended strategies, which are contrasted with realized strategies. He asserted that:

Strategy in general, and realized strategy in particular, will be defined as a pattern in a stream of decisions (where a decision is defined as a commitment to action, usually a commitment of resources). In other words, when a sequence of decisions in some area exhibits a consistency over time, a strategy will be considered to have formed. (p. 935, emphasis present in original)

By further partitioning the concept of strategy, Mintzberg intended to further operationalize the definition. However, wide agreement has not materialized as Venkatraman and Grant (1996) note, "It is especially disconcerting to find that there exists no widely accepted operational meaning for the term strategy" (p. 71).

Given that scholars are unable to reach agreement on a simple definition of strategy, it is little wonder that no common mapping of the discipline's elements has been achieved. When Mintzberg (1990) classified strategy into ten schools he concluded that, "A fuller integration of these schools must await a more intensive consideration of the empirical research" (p. 108). Concomitant with the increased interest in strategy has been a growth in the many terms used to classify published work. Beyond the simple debate of an appropriate designation for a field of study, the concepts associated with strategy are proliferating at a rapid rate. For example, in 1992, the Academy of Management Review's (AMR) index of topics had seven terms that included some form of the word strategy (Becker, 1982). By 1998, the index had grown to include 17 different uses of the term strategy (Young, 1998). 
This growth is attributable, in part, to increasing interest in the field, which is also reflected in the number of articles dedicated to the topic of strategy in management journals. The Strategic Management Journal (SMJ) has grown from seven to twelve issues annually since 1990 to accommodate the increased production of quality research in the field (Schendel, 1995). Additionally, from 1992 to 1998 the Academy of Management Journal (AMJ) articles indexed using some form of the term strategy, rose from 19 to 30 percent (McAllister, 1998; White, 1992). The expansion in $A M R$ was even more dramatic with an increase from 21 to 51 percent over the same period (Becker, 1982; Young, 1998). These indicators of increased interest in the field of strategy are conservative since many terms related to strategy are not considered in this count, such as competitive advantage, core competencies, and resource-based theory.

\section{Methods}

In order to achieve this project's primary goal, of developing a standard taxonomy, it was first necessary to identify the major areas of research in the literature and the terms used in their descriptions. The key word strategy was used to identify terms in several high quality journals that cover a variety of business disciplines.

The method for identifying terms included three steps. The first involved identifying terms associated with strategy. Second, an explicit definition for each of the terms was then recorded. Finally, criteria were established post hoc to eliminate any terms that were clearly not relevant to the field of strategy. The first and second steps are interrelated with the third since the frequency of use of a phrase serves, as one criterion for inclusion, while the ability to accurately define a concept is a critical part of the evaluation criteria. Two different types of databases were examined to compile the terms - general indices and journal indexes.

\subsection{General Indices}

There were two general indexing systems used to build an initial list of 'strategy' phrases. The two indices are structured very differently. The ABI/INFORM has a hierarchical system for arranging key terms. The Permuterm Subject Index (PSI) (1997) is a bound source that evaluates and pairs significant words in the title of every cataloged article.

ABI/INFORM evaluates and indexes journal articles without any direct input from authors. It has six major classification codes: business environment, management function, industry, market, article treatment (company or product specific), geographic, and organizational codes (multinational or diversified). Coupled with this schema is a controlled vocabulary. The 1998 lexicon was examined for this paper. Within the word list are several types of references including the authorized terms, synonymous concepts, and related terms. These relational terms are valuable because they indicate the index editors' perceptions of the field of strategy.

The PSI, on the other hand, uses very little editorial discretion in developing its index. In PSI, every significant word in a title is paired with every other significant word in the title. Therefore, the authors implicitly have far greater input into this index compared to 
ABI/INFORM. The 1997 version of the citation index was evaluated in this study. The contrast in the number of phrases available between these techniques is substantial.

\subsection{Journal Indexes}

In addition to the general indices, six high quality journals were also used in the study. The journals were selected based on Park and Gordons' (1996) 'Publication Records and Tenure Decisions in the Field of Strategic Management' article since it is directly related to strategy and journal quality (see Table 1). The journals evaluated are generally indexed by one of three methods relevant to this work, namely: titles, title subjects, or key words.

Table 1. Journals Reviewed*

\begin{tabular}{|c|c|c|}
\hline Journal & Indexing Method & Years Used \\
\hline $\begin{array}{ll}\text { Strategic } & \text { Management } \\
\text { Journal } & \\
\end{array}$ & $\begin{array}{l}\text { Key Words - Selected by author } \\
\text { with additions from journal staff. }\end{array}$ & $\begin{array}{l}\text { Five Year Index 90-94; } \\
\text { Annual Indices 95-98 }\end{array}$ \\
\hline $\begin{array}{l}\text { Administrative Science } \\
\text { Quarterly }\end{array}$ & Title & 1997,1998 \\
\hline $\begin{array}{l}\text { Academy of Management } \\
\text { Journal }\end{array}$ & Key Words - Selected by editor. & 1997,1998 \\
\hline Management Science & $\begin{array}{l}\text { Title Index, key terms included in } \\
\text { abstracts. }\end{array}$ & $\begin{array}{l}1997 \text { (1998 index issue } \\
\text { not available at time of } \\
\text { survey) }\end{array}$ \\
\hline Harvard Business Review & Titles by Subject & 1997,1998 \\
\hline $\begin{array}{l}\text { Academy of Management } \\
\text { Review }\end{array}$ & $\begin{array}{l}\text { Key Words - Selected by editor } \\
\text { with author input. }\end{array}$ & 1997,1998 \\
\hline
\end{tabular}

*Journals appear in order of ranking in Park and Gordon's (1996) article (p. 114).

Compare to other journals, Strategic Management Journal (SMJ) scored very high on both bibliometric indices of quality used in Park and Grodon's (1996) ratings (the ratio of total citations in a year to all articles ever published, and ratio of citations to articles in the previous two years divided by the number of articles). This journal was selected for extensive review because it compiles an exhaustive subject index every five years and is dedicated to the study of strategy. In addition, authors are allowed to select the key words originally used to classify their papers. The SMJ staff also added its own indexing words to each article. This provides a consistent retrospective review of concepts and terms facilitating the identification of key terms.

The most recent special index issue covered Volumes 11-15, 1990-1994. Due to the elapsed time since the last special index issue, the key terms from 1995 - 1998 annual indices were also evaluated.

The remaining journals were reviewed for the two most recent complete years available (1997 and 1998). The Academy of Management Journal (AMJ), and Academy of Management Review $(A M R)$ index by subject with key terms selected by authors. The Harvard Business 
Review (HBR) groups articles by subjects on an annual basis. Finally, Administrative Science Quarterly $(A S Q)$ and Management Science $(M S)$, provide indices by title on an annual basis. $M S$ does include key terms in the abstracts, which were reviewed for relevant terms, although not compiled in the frequency of term citation table in Table 2.

An important goal of this research was to identify the original usage of key terms and contrast them with the current usage. Therefore, when an article cited a key term and referenced it to an originating author, the original citation was obtained. When an article directly quoted a definition from a previous publication, that quotation, including citation, were used. For example, Thomas and Venkatraman (1988, p. 538) credit Hunt with coining the term 'strategic groups' and provided the following excerpt: "he (Hunt) defined it as: 'A group of firms within an industry that are highly symmetrical...(and) the personal views and preferences for various possible outcomes...' (Hunt, 1972, p.28)". If during the identification of the indexed term another phrase using the word strategy was defined, it too was cataloged ${ }^{1}$.

The method of following terms back to their originators had three distinct benefits. First, it expanded the scope of the review beyond the original six journals selected. Second, by embedding original quotes within the works of subsequent authors it dated the phrase for future researchers. Third, it reduced the potential exclusion bias by increasing the scope of review.

\section{Limitations}

The main limitation of the study is that the journals that contained only title indices $(A S Q$ in particular and $M S$ ) may not be adequately represented. $H B R$ posed a different set of concerns since it subject categorized titles and is directed toward a managers rather than researchers. The subject categorization removes many authors from the process and substitutes a few editors. This presents two problems. First, the authors may be better qualified to classify their own work. Second, it may have reduced the number of ways an article is cross-referenced.

The three phases of research met with varying degrees of success. Evaluating the various indices indicated that little attention has been given to the systematic organization of the strategy field. The journal indexes provided a great deal more information and constituted the foundation of this study. Finally, the inclusion criterion for term use frequency is straightforward, however, the use of only indexed terms would have been too restrictive to make the glossary of significant interest. Therefore, any clearly defined use of the term strategy encountered was included in the glossary although not necessarily considered in the discussion.

The ABI/INFORM system was by far the most convenient search engine to use.

\footnotetext{
${ }^{1}$ A complete glossary of the definitions and quotes compiled may be obtained from the authors.
} 
Unfortunately, its simplicity generated a limited number of searchable terms. In fact, the only terms related to strategy were strategic business units, strategic planning, strategic management, and strategy. Other related terms included competitive advantage and long-range planning. The extraordinary scarcity of terms in the ABI/INFORM system was in stark contrast to the PSI.

The PSI (1997) contained more than five full pages presenting various combinations of the term strategy with other words. Nearly every relative term indexed in the major journals appeared somewhere in the SSCI. In addition to the relative terms, a huge number of unrelated expressions that merely had the word strategy somewhere in their title also were included. The large number of unrelated expressions made the use of the PSI impractical for this study.

\section{Results}

The review of the most recent years' SMJ (95-98), AMJ (97-98), HBR (97-98), and AMR (97-98) yielded 66 different terms using some form of the word strategy (see Table 2). Altogether there are 288 references to articles. However, the actual number of articles was considerably smaller since many were cited multiple times. There were 23 terms that met the initial inclusion criteria of three or more citations. Ultimately, 50 terms and numerous definitions entered the glossary. The glossary is far from exhaustive, however, and many of the terms have already achieved consensual definitions. Nevertheless, in the interest of comprehensiveness, no definition once identified was removed.

Of the 66 major terms used among all of the journals, SMJ used 52 over a four-year period. $S M J$ and $A M R$ each averaged 19 different citation terms per year. However, $A M R$ made use of links within the index thus inflating its overall count. $A M J$ and $H B R$ used only nine and two indexing categories respectively in 1998. Of the 66 major terms only 23 met the relatively modest threshold of being used more than three times, there is clearly a need to analyze the classification criteria used for journal articles.

A common understanding of how the strategy literature is organized is urgently needed and the current ad hoc method, in which each journal employs its own methodology, only increases the confusion. As of yet no system has been proposed. Therefore, introduction of a standard taxonomy may be most beneficial in achieving Leontiades's original objectives.

\section{Indexing Proposal}

A great deal of the confusion in the strategy field begins with the lack of parsimony in the selection of key words. The development of an agreed upon classification system would make strategy research indexing much more uniform and useful.

A method for developing and refining such a classification system is the purpose of the remainder of this paper. Adopting the schema from another discipline may be the simplest and quickest route to developing a classification system for strategy publications. The Journal of Economic Literature (JEL) employs a well-developed system that is widely used 
by economists.

The proposed strategic taxonomy is modeled after the $J E L$ system. It is a three-tiered system used in classifying economic journal articles. The first level is denoted using capital letters. The same letter and a single numeral indicate the second series of headings. The finest level of headings further partitions the second tier by adding another number. For example, in the economic system, code L12 is Monopoly and Monopolization Strategies, which is a sub-heading of L1 - Market Structure, Firm Strategy, and Market Performance, which in turn is a classification under $\mathbf{L}$ - Industrial Organization. Two numbers have special designations throughout the indexing. A zero or a nine in any position represent 'general' and 'other' topics in the relevant category respectively. By design, this schema limits the level of abstraction possible.

Table 2. Indices summary of major strategy journals using variations of the word 'strategy' to categorize articles

\begin{tabular}{|c|c|c|c|c|c|c|c|c|c|c|c|}
\hline \multirow[b]{2}{*}{ Index Term / Year } & \multicolumn{4}{|c|}{$\begin{array}{l}\text { Strategic } \\
\text { Management } \\
\text { Journal }\end{array}$} & \multicolumn{2}{|c|}{$\begin{array}{l}\text { Academy of } \\
\text { Management } \\
\text { Journal }\end{array}$} & \multicolumn{2}{|c|}{$\begin{array}{l}\text { Harvard } \\
\text { Business } \\
\text { Review }\end{array}$} & \multicolumn{2}{|c|}{$\begin{array}{l}\text { Academy of } \\
\text { Management } \\
\text { Review }\end{array}$} & \multirow[t]{2}{*}{ Total } \\
\hline & 95 & 96 & 97 & 98 & 97 & 98 & 97 & 98 & 97 & 98 & \\
\hline Acquisition strategy & 1 & & & & 4 & 1 & & & $1 * *$ & & 7 \\
\hline Business strategy & 1 & & & & 8 & & & & 2 & 2 & 13 \\
\hline Competitive & 1 & 1 & & & 2 & & & & & & 4 \\
\hline Communication & & & & & & & & & 1 & 1 & 2 \\
\hline Cooperative & 1 & & & & & & & & & & 1 \\
\hline Core strategies & & & & 1 & & & & & & & 1 \\
\hline Corporate strategy & 1 & & 2 & 1 & 5 & & & 2 & 2 & 2 & 15 \\
\hline Culture \& strategy & 1 & & & & & & & & & & 1 \\
\hline $\begin{array}{l}\text { Cross-national } \\
\text { strategy }\end{array}$ & & & & 1 & & & & & & & 1 \\
\hline Diversification & & & 1 & & & & & & 1 & & 2 \\
\hline Entry strategy & 1 & 1 & 1 & & 1 & & & & & & 4 \\
\hline Environmental & 1 & & & 1 & & & & & & 1 & 3 \\
\hline Generic strategies & 1 & & & & & & & & & & 1 \\
\hline Global strategic & 1 & & & 1 & & & & & & & 2 \\
\hline Inter-organizational & 1 & & & & & & & & & & 1 \\
\hline International & & 1 & 1 & & 4 & & & & & & 6 \\
\hline Japanese strategy & 1 & & & & & & & & & & 1 \\
\hline Manufacturing & & 1 & & & & & & & & & 1 \\
\hline $\begin{array}{l}\text { Multinational } \\
\text { strategy }\end{array}$ & & & & 1 & & & & & & & 1 \\
\hline New venture & & & & & & & & & 1 & & 1 \\
\hline Operations strategy & & & 1 & & & & & & & & 1 \\
\hline Political strategy & & & & 1 & & & & & & & 1 \\
\hline Product strategy & & & 1 & & & & & & & & 1 \\
\hline Resource-based & 1 & & & & & & & & & & 1 \\
\hline Specialist strategies & & & & 1 & & & & & & & 1 \\
\hline
\end{tabular}




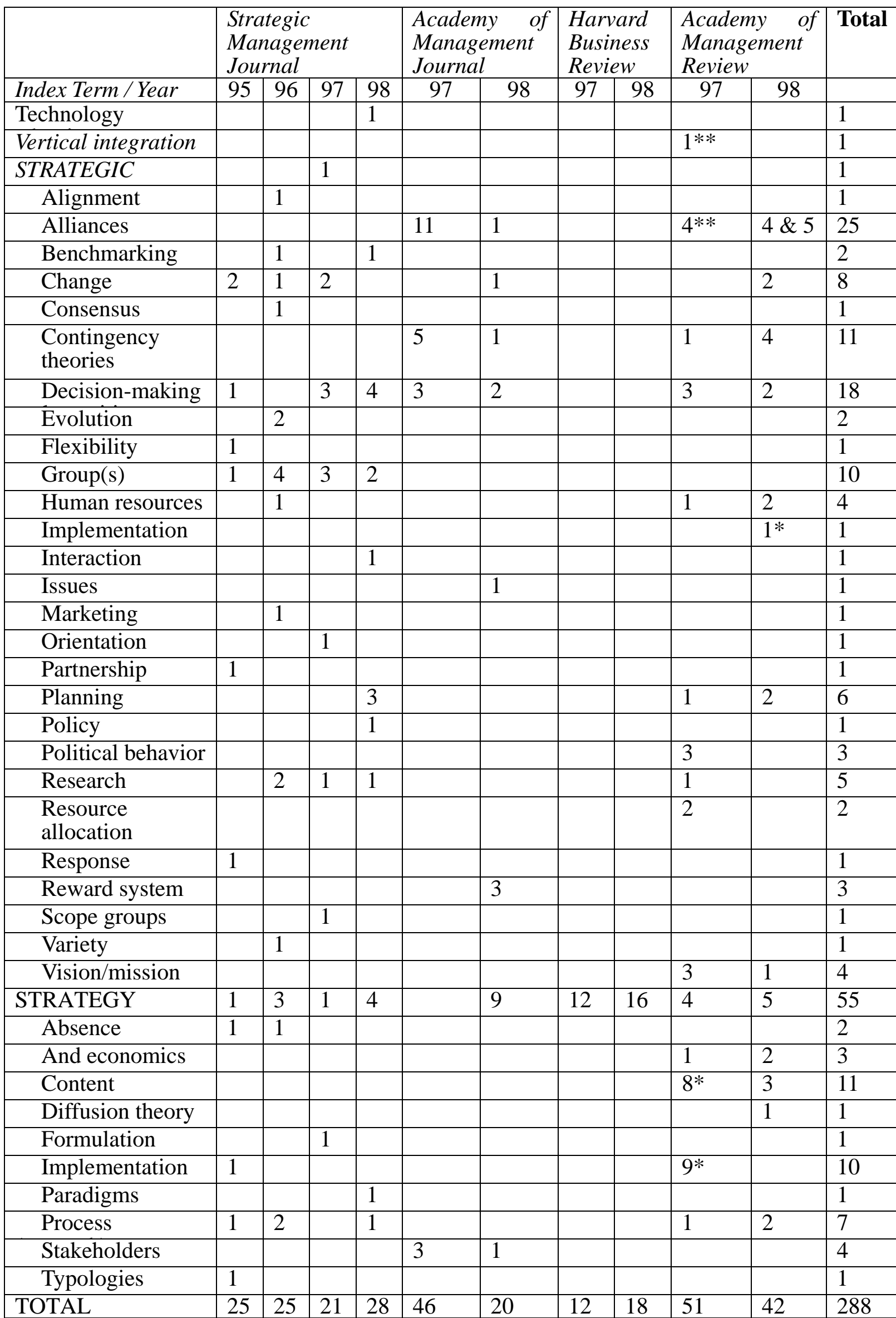


Journals selected based on Park and Gordon's (1996) evaluation of tenure value. Two of the top tier journals, Administrative Science Quarterly and Management Science, are omitted since they only index by author and title. * With several subheadings also listed. ** See content

*** A complete glossary of definitions with citations is available from the authors

The two major limitations are artifacts of the alphabet's size and the number of Arabic numerals available. The alphabetic limitation could be easily overcome by adding a letter to the first tier designators. However, allowing this to happen would be unadvisable for two reasons. First it defeats the purpose of developing the most parsimonious system possible. Second, if other areas of business were to adopt this proposal, that would be the appropriate time to add a second letter to indicate different disciplines.

The numeric restriction is also desirable since it limits the number of possible subheadings to eight (10 numerals minus 0 and 9). Therefore, any second or third-tier category that has more than eight major components will have to be further subdivided at a higher level. The 'other' categories, indicated by the number nine, serve as a valuable marker in the maintenance of the system. Disproportionate numbers of articles being classified in the 'other' categories may indicate a dedicated stream of literature that needs to be added to the index. Nevertheless, it remains to be seen whether this restraint will create major problems with the final listing, it is only a minor concern in the draft proposal.

The draft proposal has nine first-level categories, 64 second-tier headings, and 117 third degree classes. It is important to remember that the second and third levels often have 'general' and 'other' headings, thus inflating their counts. When convenient the letters assigned to the major headings match their titles. There are four significant exceptions. The letter ' $A$ ' is dedicated to General Strategy, Teaching, and Publication. 'B' is used to designate the History of Strategy Thought. In addition to general and history classifications, it is logical that every business discipline should have Qualitative and Quantitative Research Methods and Theories sections. Therefore, these two areas are indicated using the letters ' $Q$ ' and ' $T$ ' respectively. In fact, research methods did appear twice in the index review under strategic management (5 citations) and strategy process ( 7 citations). The other five broad areas in the schema were selected based on the index and literature reviews.

The entire draft proposal is contained in Table 3. The four headings mentioned previously are generic to most social sciences and no further explanation will be offered here. The remaining five will certainly prove to be more controversial.

C - Competitive Advantage, despite appearing infrequently in the recent indexes of major strategy journals, is nevertheless a major area of research. For example, SMJ's five-year index (Schendel, 1995) had nearly 30 articles directly attributed to competitive or sustained advantage. In many respects this is the essence of strategy. Concepts such as mergers, acquisitions (7 citations), and divestiture, which do appear frequently, may be included in this classification. 


\section{Macrothink}

D - Decision-Making, on the other hand, did appear 18 times (see Table 2). Further, several authors (Eisenhardt \& Zbaracki, 1992; Rajagopalan, Rasheed, \& Datta, 1993; Schwenk, 1990) have sought to organize this literature into related streams of research. Their conclusions are also incorporated into the schema and noted accordingly.

E - Environment also failed to be mentioned regularly in the most recent sets of indexes. However, the debate between determinism and choice centers around environmental issues. Further, the volumes of literature dedicated to Industry and TOWS (threats, opportunities, weaknesses, and strengths,) analysis warrant inclusion in some area. An environmental category meets these needs.

$\mathbf{P}$ - Performance and $\mathbf{S}$ - Structure are the last two major headings proposed in this draft classification. Performance is closely related to the research methods category since it is often the measurement of performance that confounds strategy studies. But, because of the very importance of agreement on these measures it warrants its own heading. The relationship between strategy and structure is so significant that little explanation is necessary. The category does make a convenient home for sub-headings such as Mergers, Acquisitions, and Divestiture (S3), Alliances (S4), and Stakeholders (S5).

Table 3. Proposed classification system for journal articles

\begin{tabular}{|l|l|}
\hline A - General strategy, teaching, and publication \\
\hline A0 General & A14 Corporate-level Strategies \\
\hline A1 Strategy (Content) & A15 Business-level Strategies \\
\hline A10 General & A16 Competitive Strategies \\
A11 Theory Development & A19 Other \\
A12 Role of Strategy Researcher & A13 Scope of the Firm \\
\hline A2 Strategic Management (Process) & A25 Integrated Approaches \\
\hline A20 General & A26 Role of Strategists / Manager \\
A21 Formulation & A27 Strategic Thinking \\
A22 Implementation & A29 Other \\
A23 Normative Approaches & \\
A24 Descriptive Approaches & A39 Other \\
\hline A3 Teaching & \\
\hline A30 General & A42 Texts \\
A31 Case Study Method & A44 Web-sites \\
\hline A4 Publication & A49 Other \\
\hline A40 General & \\
A41 Journals & \\
A42 Books & \\
\hline A9 Other & \\
\hline B - History of strategy thought & \\
\hline B0 General &
\end{tabular}




\section{Macrothink}

B1 History of Strategic Thought Prior to 1979

\begin{tabular}{l|l} 
B10 General & B13 Strategic Planning \\
B11 Long-range Planning & B19 Other \\
B12 Business Policy &
\end{tabular}

B2 History of Strategic Thought Since 1979

B3 Strategy's Relation to Other Disciplines

\begin{tabular}{l|l} 
B30 Economics & B35 Political Science \\
B31 Finance & B36 Engineering \\
B32 Psychology & B37 Anthropology \\
B33 Management Sciences & B39 Other \\
B34 Sociology &
\end{tabular}

B9 Other

$\mathrm{C}$ - Competitive advantage

C0 General

C1 Rents

C2 Barriers

C20 General

C21 Entry

C22 Mobility

C29 Other

C3 Scale and Scope

C4 Human Resources

C5 Regulation

C6 Global

C7 Mergers, Acquisitions, and Divestiture

C8 Entry Strategies

C9 Other

D-Decision making

D0 General

D1 Models and Characteristics

\begin{tabular}{l|l} 
D10 General & D12 Environmental Influences
\end{tabular}

D11 Rationality and Bounded Rationality

D19 Other

D2 Biases

D20 General

D29 Other

D21 Garbage Can Model

D3 Individual and Organizational Minds

D30 General

D31 Organizational Influences

D4 Upper Echelon

D40 General

D41 Politics and Power

D42 CEO

D49 Other

D6 Competitive Decisions

D60 General

D61 Performance Effects

D5 Information Technology

D39 Other

\begin{tabular}{l} 
D42 CEO \\
D49 Other \\
\hline
\end{tabular}

D69 Other 
D7 International Context

D9 Other

E - Environment

E0 General

E1 Deterministic

E2 Strategic Choice

E20 Strategic Fit

E21 Environmental Strategies

E22 Flexibility

E29 Other

E3 Change

E4 Strategic Issues

E5 Cognition

E50 General

E51 Intentions

E53 Computations

E52 Representations

E6 Crisis

E7 Analysis

E70 General

E59 Other

E71 SWOT

E72 Industry

E79 Other

E8 International

E9 Other

$P$ - Performance measures

P0 General

P1 Financial

P10 General

P11 Accounting

P12 Non-Accounting

P19 other

P2 Economic

P20 General

P21 Market Share

P22 Growth

P29 Other

P9 Other

$\mathrm{Q}$ - Qualitative and quantitative research methods

Q0 General

Q1 Econometric and Statistical Methods

Q10 General

Q11 Hypothesis Testing

Q12 Estimation

Q19 Other

Q2 Field Research

Q20 General

Q21 Interviews

Q23 Scenario Methods

Q22 Case Studies

Q29 Other

Q3 Typologies

Q30 General

Q31 Miles and Snow

Q32 Porter's Generic Strategies

Q4 Strategic Groups

Q40 General

Q43 Cognitive Measures 
Q41 Multivariate Tests

Q44 CFA

Q42 Cluster Analysis

Q49 Other

Q5 Surveys

Q50 General

Q51 Likert Scales

Q53 Q-Sorts

Q52 Guttman Scaling

Q54 Delphi Methods

Q59 Other

Q9 Other

S- Structure

S0 General

S1 Asset

S2 Organizational

S3 Mergers, Acquisitions, and Divestiture

S4 Alliances

S4 Stakeholders

S9 Other

$\mathrm{T}$ - Theories

T0 General

T1 Resources

T10 General

T11 Resource-based View

T13 Transaction Cost Theory

T12 Resource Dependency Theory

T19 Other

T2 Agency Theory

T3 Theory of the Firm

T30 General

T31 Relational

T32 Contractual

T33 Relational - Contracting

T34 Team Production Theory

T39 Other

T4 Game Theory

T5 Social Learning Theory

T6 Evolutionary Theory

T7 Stakeholder Theory

T8 Diffusion Theory

T9 Other

There are two general concerns regarding the proposed system. First, should major categories be orthogonal? In the draft system, Mergers, Acquisitions, and Divestiture appears twice (C7 and S3 in Table 3). It is possible, and perhaps desirable to limit the use of any category to one group. For example, if acquisition is confined to structure, and an author wants to discuss it relative to competitive advantage they would select S3 and C0 to convey this relationship. The second concern is that draft system has more terms than the sum of the indexed journals.

However, consider the more comprehensive index prepared by $S M J$. The five-year version issued in 1994 contains 36 pages of indexing and hundreds of different entries, some with only minor variations. This proposal would be considerably more parsimonious than that 
alternative. Further, this research only considered terms containing the word strategy. It is difficult to determine how many other citations may have been included otherwise. Nevertheless, SMJ's version is superior if a researcher is looking for only one very specific article. An author's name search would suffice in this case. In addition, in journals where the editors provide the annual indexing there is the distinct possibility of misclassification.

One natural advantage of the proposed system is that its constraints will automatically serve to identify major streams of literature. For example, it is very likely that the two areas may warrant their own major headings -- content and process. In the current proposal they are placed under the general heading. To determine the appropriate categories some form of consensus is desirable.

\section{Recommendations and Conclusions}

The Delphi process, a common research method for developing consensus, is desirable for three reasons. The primary objective is to develop the best strategy taxonomy possible, one that is comprehensive yet parsimonious. It is unlikely any single individual could do so in a timely fashion. Therefore, involving the best minds in management science is logical. Second, having scholars accept the schema is as important as developing it thoroughly. Participation in the development process should facilitate its acceptance by scholars. Third, there is a modification to the Delphi method that may heighten interest in the project and hasten its completion.

Using decision support software in the Delphi process may provide several advantages. The immediacy of the Internet eliminates the need for numerous rounds of mailings traditionally used to reach consensus. The software also removes the potential biases introduced as the mediator consolidates iterative rounds of Delphi surveys. Further, the software gives participants continual feedback regarding the level of consensus achieved. For the purpose of this project, members may decide that consensus is not necessary on every issue and choose to select an acceptable level of agreement

There is an urgent need to organize the literature in strategy. To accomplish this it was first necessary to identify the major content areas that have been developed by scholars. Next, a preliminary classification system has been developed, presented, and explained. Finally, it is recognized that the proposed system is an initial draft and should be widely discussed and carefully refined.

\section{References}

Social Sciences Citation Index. (1997). Permuterm Subject Index: A to Z . Philadelphia, PA: Institute for Scientific Information, Inc.

Barry, D., \& Elmes, M. (1997). Strategy Retold: Toward a Narrative View of Strategic Discourse. Academy of Management Review, 22(2), 429-452.

Becker, T. E. (1982). Subject Index. Academy of Management Review, 17(4), 836-839. 
Chandler, A. D., Jr. (1962). Strategy and Structure: Chapters in the History of the American Industrial Enterprise. Cambridge, Mass.: The MIT Press.

Eisenhardt, K. M., \& Zbaracki, M. J. (1992). Strategic Decision Making. Strategic Management Journal, 13(4), 17-37.

Hoskisson, R. E., Hitt, M. A., Wan, W. P., \& Yiu, D. (1999). Theory and research in strategic management: Swings of a pendulum. Journal of management, 25(3), 417-456.

Hunt, M. S. (1972). Competition in the major home appliance industry, 1960-1970. Unpublished doctoral dissertation, Harvard University.

Kuhn, T. S. (2012). The structure of scientific revolutions: 50th Anniversy Edition. University of Chicago press.

Leontiades, M. (1982). The Confusing Words of Business Policy. Academy of Management Review, 7(1), 45-48.

McAllister, D. (1998). Subject Index. Academy of Management Journal, 41(6), 734-735.

Mintzberg, H. (1978). Patterns in Strategy Formation. Management Science, 24(9), 934-948.

Mintzberg, H. (1990). Strategy Formation: Schools of Thought. In J. W. Fredrickson (Ed.), Perspectives on Strategic Management . New York, NY: Harper Business.

Nicolai, A. T., \& Dautwiz, J. M. (2010), Fuzziness in Action: What Consequences Has the Linguistic Ambiguity of the Core Competence Concept for Organizational Usage?. British Journal of Management, 21, 874-888. http://dx.doi.org/10.1111/j.1467-8551.2009.00662.x

Park, S. H., \& Gordon, M. E. (1996). Publication Records and Tenure Decisions in the Field of Strategic Management. Strategic Management Journal, 17, 109-128.

Rajagopalan, N., Rasheed, A. M. A., \& Datta, D. K. (1993). Strategic Decision Process: A Critical Review and Future Directions. Journal of Management, 19, 349-384.

Ronda-Pupo, G. A., \& Guerras-Martin, L. Á. (2012), Dynamics of the evolution of the strategy concept 1962-2008: a co-word analysis. Strategic Management Journal, 33, 162-188. http://dx.doi.org/10.1002/smj.948

Schendel, D. E. (1995). Introduction to the Five Year Index Volume. Strategic Management Journal, 16, 1-2.

Schendel, D. E., \& Hofer, C. W. (1979). Strategic Management: A New View of Business Policy and Planning. Boston: Little, Brown and Company.

Schendel, D. E. (2006). Introduction to the Five-Year Index. Strategic Management Journal, 27, Index Issue, iii-v.

Schwenk, C. (1990). Strategic Decision Making. Journal of Management, 21, 471-493.

Thomas, H., \& Venkatraman, N. (1988). Research on Strategic Groups: Prognosis and Diagnosis. Journal of Management Studies, 25(6), 537-555.

Venkatraman, N., \& Grant, J. H. (1996). Construct Measurement in Organizational Strategy Research: A Critique and Proposal. Academy of Management Review, 11(1), 71-87.

White, M. A. (1992). Subject Index. Academy of Management Journal, 35(5), 1120-1121. 
Young, G. (1998). Subject Index. Academy of Management Review, 23(4), 829-831.

\section{Copyright Disclaimer}

Copyright reserved by the author(s).

This article is an open-access article distributed under the terms and conditions of the Creative Commons Attribution license (http://creativecommons.org/licenses/by/3.0/). 